IAC-04-V5.01

\title{
TECHNOLOGY INNOVATIONS FROM NASA'S NEXT GENERATION LAUNCH TECHNOLOGY PROGRAM
}

\author{
Stephen A. Cook \\ Stephen.A.Cook@nasa.gov \\ Charles E. K. Morris, Jr. \\ Charles.E.Morris@nasa.gov \\ Richard W. Tyson \\ Richard.W.Tyson@nasa.gov
}

NP01, NASA Marshall Space Flight Center

Huntsville, Alabama, USA 35812

\begin{abstract}
NASA's Next Generation Launch Technology Program has been on the cutting edge of technology, improving the safety, affordability, and reliability of future space-launch-transportation systems. The array of projects focused on propulsion, airframe, and other vehicle systems. Achievements range from building miniature fuel/oxygen sensors to hot-firings of major rocket-engine systems as well as extreme thermo-mechanical testing of large-scale structures. Results to date have significantly advanced technology readiness for future space-launch systems using either airbreathing or rocket propulsion.
\end{abstract}

\section{INTRODUCTION}

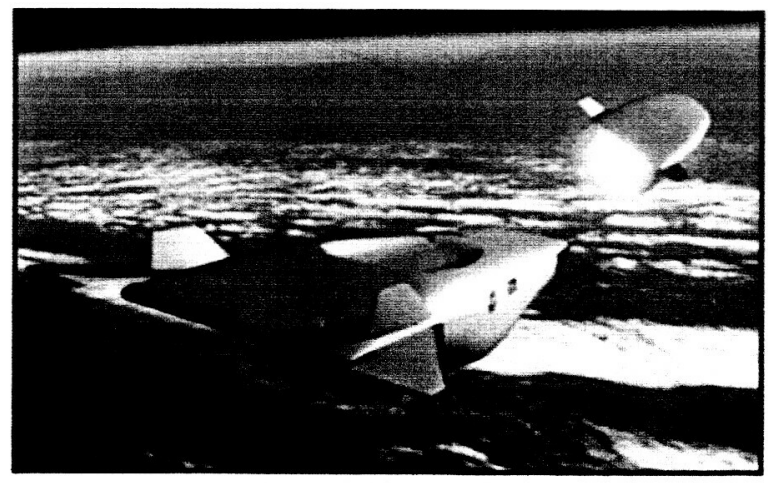

Fig. 1: Airbreathing-propulsion first stage.

NASA formulated the Next Generation Technology (NGLT) Program to advance the stateof-the-art in critical and high-payoff technologies for future generations of space-launchtransportation systems. NGLT technologies were to provide for lower costs, more reliability, and greater safety for the full range of earth-to orbit transportation concepts and architectures options that range from man-rated, partially reusable systems to fully expendable launchers. In general, NGLT addressed technologies that were not yet technically or economically feasible.

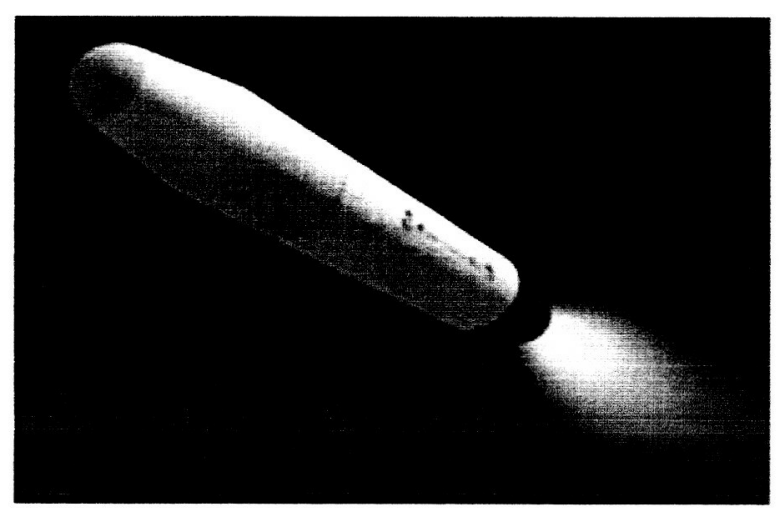

Fig. 2: Expendable rocket-powered booster.

NASA organized the NGLT program into sets of 
projects for propulsion, airframe/vehicle systems, operations, and flight demonstrations. (The latter primarily focused on hypersonic, airbreathing propulsion.) Dedicated efforts for systems analysis and integration supported the planning and evaluation processes.

The NGLT Program derived its content largely from prior programs: the Second-Generation (2nd-Gen) /Reusable Launch Vehicle (RLV) Program and the Advanced Space Transportation Program (ASTP). The 2nd-Gen/RLV Program's technologies supported development of reusable, rocket-powered, space-launch systems anticipated to replace the U.S. Space Shuttle. In contrast, ASTP's vision was for vehicle concepts with air-breathing propulsion for first-stage boosters; program emphasis was on the long term (e.g., for a new mode of space launch to become operational within several decades). As a combination of these two precursor programs, NGLT incorporated all of NASA's major, longer-term investments in space-launch technologies.

NASA's plan was to assess NGLT technology status periodically to determine if a specific space-launch vehicle and associated architecture could be selected for implementation in the future. If the technologies were ready and the architecture met projected needs, the selection would lead to a new program for that particular vehicle and architecture. The new program would incorporate any on-going NGLT work that directly supported the new program's goals.

The new system could have been an expendable or a reusable launch system - NGLT was to enable virtually any feasible architecture.

As a result, the various NGLT projects had notably different objectives and content. One project sought to advance to prototype-engine development for a large rocket engine that burns kerosene and liquid oxygen (LOx). Another sought to achieve a ground-based demonstration of a turbine engine capable of Mach-4 flight, while yet another focused on in-flight demonstrations, at Mach 5 to 7 , of airframe-integrated scramjets. Other projects addressed specific challenges for subsystems or components such as space-based, range-safety operations or cryogenic-fuel tanks made with composite materials. In short, the total list of NGLT technologies was extremeiy varied.

NASA's overall plan involving future spacelaunch systems changed in January of this year when President Bush announced a new vision for NASA space exploration (ref. 1). While the achievements of the NGLT program contributed to the foundation for the new vision, the NGLT program itself has concluded. Several of the projects will continue to complete products that directly support the President's vision.

This paper provides an overview of hardwarerelated accomplishments of the projects which, taken collectively, constitute the NGLT program. There is no overview of the entire program's organization or history. This paper first addresses technologies for: rocket-propulsion, then air-breathing propulsion, and, finally, airframe systems and vehicle operations.

\section{ROCKET-PROPULSION}

NGLT modified and then continued a series of projects already developed under the 2 ndGen/RLV program. That program had primary requirements derived from the needs for reusable systems. These requirements typically addressed both reusability and reliability, so as to increase safety and enhance operability. While the four projects in this set included plans for ground-based testing, each project's emphasis remained on technology, not development of operational hardware.

\section{Rocket Engine Prototype}

The Rocket Engine Prototype (REP) Project was conceived in the 2 nd Gen/RLV program to advance technologies for a million-pound-thrustclass, oxygen/kerosene engine. Technologies for advanced design tools and oxygen-rich, staged combustion were anticipated to yield high reliability at reasonable cost; project plans called for validation through ground-based testing of a full-scale, fully integrated, engine system. Boeing Rocketdyne, prime contractor for this work, designated the resulting prototype engine as the RS-84 (ref.2). 


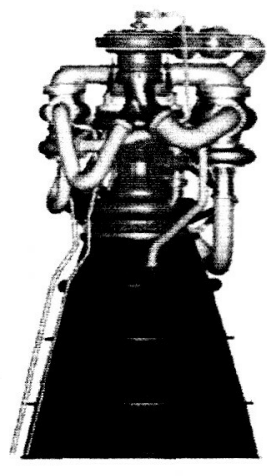

Fig. 3: RS-84 Prototype Engine

Successful cold- and hot-fire tests of the first of several configurations of one-fifth-scale preburners produced data (and 40,000 pounds of thrust) at NASA Stennis Space Center. The data set included combustion performance and stability, system durability and combustionproduct uniformity.



Fig. 4: RS-84 Preburner Tests

A Rocketdyne trade study helped define the final engine configuration that had two separate turbopumps, which allowed for optimization with different turbine speeds for each pump. The supporting analyses led to having two separate units, instead of one shaft linking two turbines, thus avoiding the danger of a single-shaft failure mode (e.g. single-pump runaway).

REP achieved notable success in demonstrating compatibility of an uncoated, high-strength alloy with operations in a high-pressure, high- temperature, oxygen-rich environment. The hotflow tests at NASA White Sands Test Facility reached extreme conditions for 10,000 pounds per square inch) with gaseous oxygen. This demonstrated significant potential for improved reliability at reasonable cost.

NASA Glenn Research Center (GRC) completed heated-tube testing that pumped standard-grade RP-1 (kerosene) through conventional copper tubing to simulate fuel cooling of the combustion chamber and nozzle. The deposition of copper sulfides inside the tubes led to significant pressure drops -- confirming the need for operations with a low-sulphur grade of RP-1.

The REP Project also tested two types of turbine design. NASA accomplished the first test, with Rocketdyne participation, in the turbine-airflow test rig at NASA Marshall Space Flight Center. Results characterized blade loading and dynamic response for an instrumented, rotating-turbine test section that was representative of the turbines in both of the RS- 84 high-pressure turbopumps.

Next, the project completed whirligig test involved spinning a bladed turbine disk, modeled after RS-84 turbopump designs. While it spun at speeds up to $34,000 \mathrm{rpm}$, streams of highpressure nitrogen excited the turbine-blade dynamic modes. Those results demonstrated the level of blade-motion damping required for turbine reliability and, hence, long life.

\section{Integrated Powerhead Demonstrator}

A partnership between NGLT and the Air Force Research Laboratory (AFRL) is demonstrating new technologies for a full-flow, stagedcombustion rocket engine using oxygen and hydrogen as propellants in the Integrated Powerhead Demonstration (IPD) project. The technologies include those for long-life components, a wide range for throttling and oxygen-rich turbine systems -- all integrated into a demonstrator engine with 250,000 pounds of thrust.

NASA Marshall Space Flight Center manages NGLT responsibilities, which include acting as the government's technical lead organization and testing at NASA Stennis Space Center. 
AFRL manages the contracts of the two prime contractors, which are Aerojet and Boeing Rocketdyne.

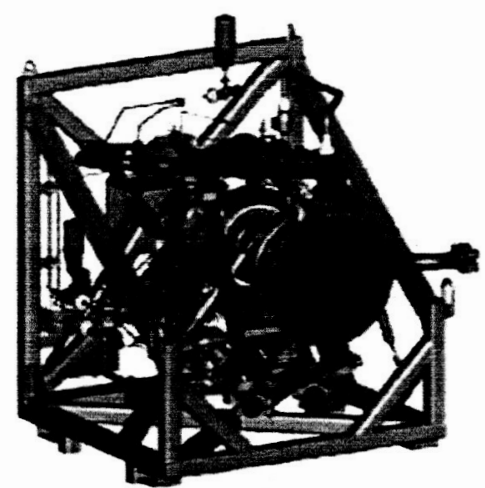

Fig. 5: IPD engine system in facility mount

Hot-fire testing of the oxygen turbopump in 2003 at Stennis proved the feasibility of key technologies for improving reliability and operability for next-generation, LOx, rocket turbomachinery that uses hydrostatic bearings and clutching bearings plus oxygen-compatible materials at high pressures. Later, the IPD Project performed component testing of an advanced liquid-hydrogen turbopump at Stennis. In addition to validation of the hydrostatic and clutching bearing designs, materials in the turbine proved resistant to hydrogen embrittlement as a way to avoid use of protective coatings. These turbines were designed to allow greater massflow rates, resulting in lower turbine-operating temperatures for a given level of engine thrust.

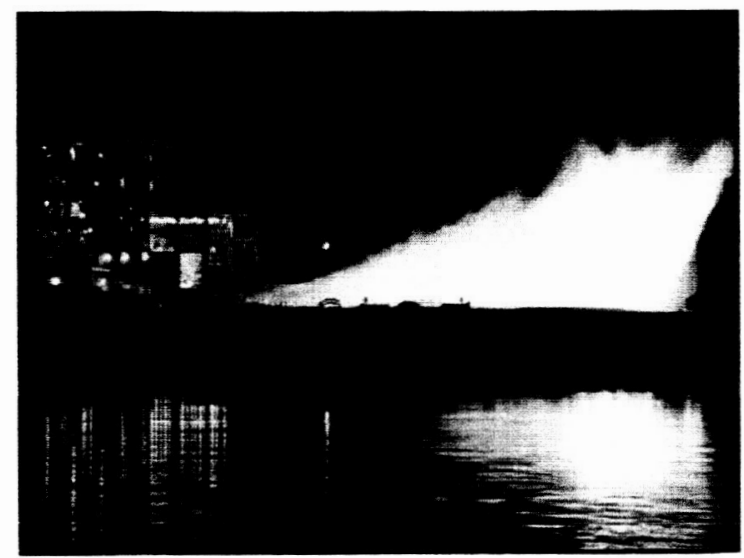

Fig. 6: IPD hydrogen-pump test
Under the IPD project, the Aerojet Corporation tested the first large-scale, flight-weight, oxygen-rich preburner in the United States at its facility in Sacramento, California. The preburner design allowed for throttling to low-power settings while minimizing the temperature variations in the preburner's oxygen-rich steam coupled with material selection to minimize the risk of ignition in the presence of the hot, highpressure oxygen gas. Successful tests covered start sequences, various propellant-mixture ratios and throttling.

Several key technologies will be tested initially during the upcoming engine test series. Among the component technologies, are: the first U.S. large-scale, gas-gas main injector, a channelwall nozzle and advanced main-combustionchamber concept. (The channel-wall construction promises to increase durability over the conventional tube-type nozzle designs.)

\section{Auxiliary Propulsion Project}

The Auxiliary Propulsion Project (APP), as initiated under the 2 nd-Gen/RLV program, addressed technology gaps and risks in the development of non-toxic and cryogenic propellants for future auxiliary-propulsion applications. The applications include reaction-control engines and orbital-maneuvering engines, as well as the storage, control, and transfer technologies associated with on-orbit storage of cryogens.

On-orbit propulsion systems and reactioncontrol systems for launch vehicles and spacecraft provide for attitude control and/or maneuvering at very high altitude or in space. Traditional on-orbit propulsion systems, including those of the NASA Shuttle, use toxic propellants that are dangerous, expensive and environmentally unfriendly. The APP project has primarily focused on oxygen-based systems but also performed some tasks on peroxidebased systems. The project has taken a systems approach - not only focusing on engines but also on tanks, feed-systems and propellantmanagement techniques relative to long-term operation in microgravity. 


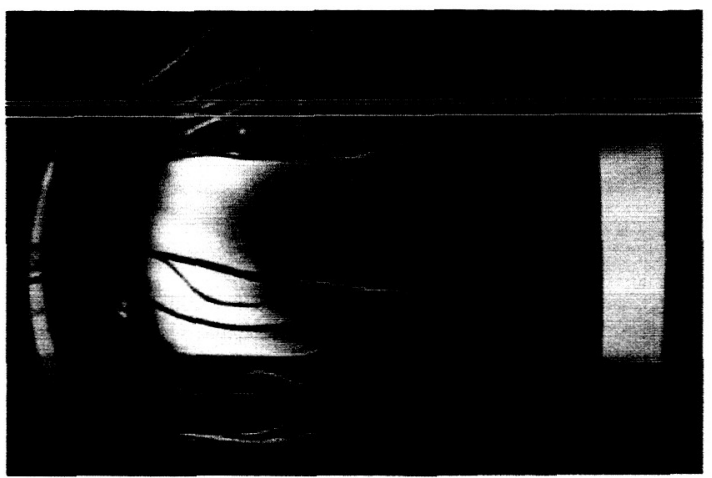

Fig. 7: APP vernier-engine hot-fire test

In late 2003, APP began testing a LOx/ethanol, reaction-control engine (RCE) at Gen Corp Aerojet facilities in Sacramento, California. The engine was designed to operate in a dual mode, with separate sets of valves used for vernier mode (limited to 25 pounds of thrust) and for the primary mode (at 870 pounds of thrust). One significant finding of the vernier testing was confirmation of the ability to start and operate a small thruster using liquid oxygen without the need for pre-injection gasification. Results determined the need for further design trades on steady-state versus pulsing performance for the vernier mode.

In mid 2004, testing at Gen Corp's Aerojet facilities resulted in over 3640 pulses and 1847 seconds of hot-fire operation for long duration, pulses and throttled thrust representative of typical ascent, on-orbit, and re-entry operations. The LOx/ethanol RCE test demonstrated the ability to operate in a pressure-fed application without turbo-pumps or separate heat exchangers.

In 2003, APP concluded work on component technologies for Rocket-Grade Hydrogen Peroxide (RGHP), which was investigated because of its potential use as a non-toxic, roomtemperature, storable oxidizer to replace LOx or toxic/carcinogenic, room-temperature oxidizing compounds. Early work explored peroxidedetonation sensitivity (to pressure/temperature combinations), materials compatibility, JP-8based hypergolic-fuel characterization, and the applicability of propellant-management techniques. These efforts added to the general tech- nical knowledge database relative to the safe, efficient use of hydrogen peroxide in rocketpropuision applications (ref. 3 ).

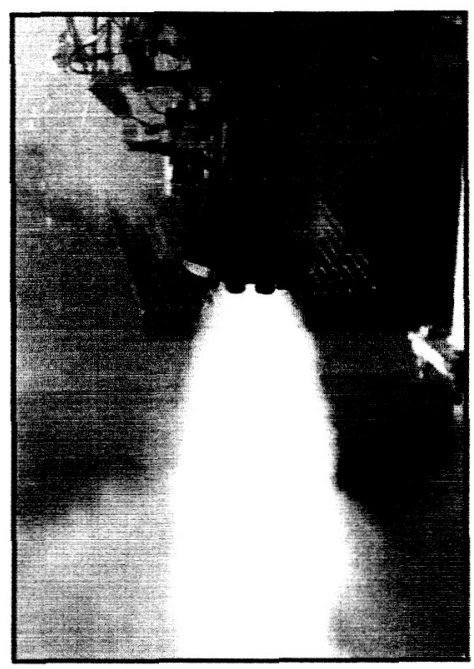

Fig. 8: Peroxide/hypergolic injector test

Cryogenic-fluid management for on-orbit propulsion systems presents many challenges relative to propellant storage and delivery. In order to minimize the size and weight of the tank, it is desirable to store propellants at high density and low pressure. Many non-toxic, on-orbit propulsion concepts utilize cryogenic propellants, such as LOx, and typically require the undesirable option of active cooling and venting in space. (Active refrigeration adds complexity and weight, whereas venting not only imparts unwanted thrust on the vehicle but also wastes propellants.)

On-orbit microgravity complicates efforts to deliver propellants uniformly to the tank outlet or even to vent only vapor overboard. Additionally, a "gravity-enabled," automobiletype, gas gauge cannot function for propellant disbursed throughout a tank in microgravity. Future test at NASA Marshall will address approaches to address pressure control, while tests at Glenn Research Center will use capillary or surface-tension devices for liquid delivery and will test optical systems for gauging liquid volume. 


\section{Propulsion Technology and Integration}

A series of sub-projects within the Propulsion Technology and Integration (PT\&I) Project advanced subsystem and component level technologies for rocket-propulsion systems.

Northrop Grumman Space Technology, Inc. successfully completed testing of a reactioncontrol subsystem with a 120 -second firing of a thruster using a new Platinum-Iridium (Pt-Ir) combustion chamber at their Capistrano Test Site in California. The use of LOx/ethanol propellants provided for technology improvements for reusable, non-toxic, small-thruster application. The use of the Pt-Ir alloy avoided the need for lining the chamber with coatings, which typically lack durability. These advancements should lead to increased safety and decreased operational costs (ref. 4)

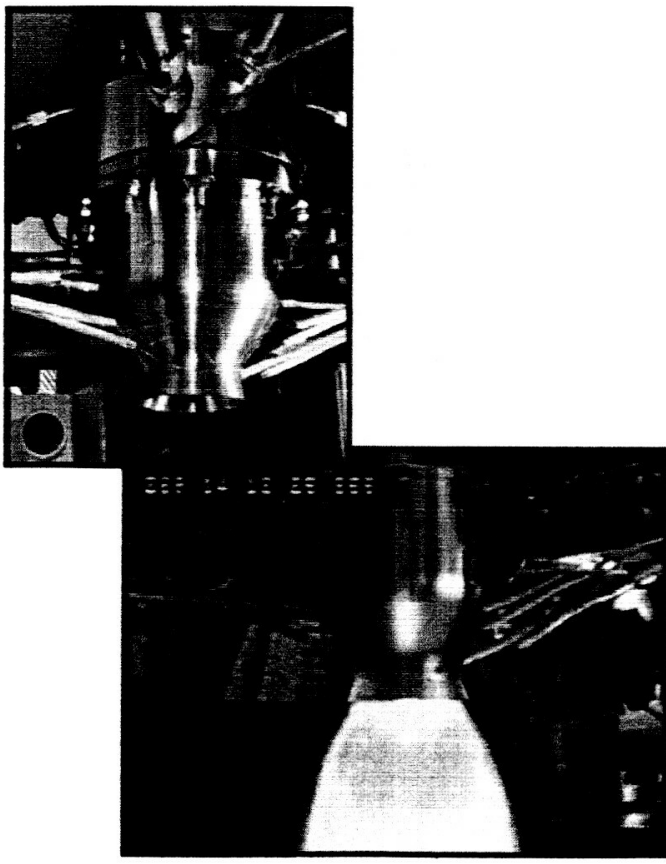

Fig. 9: PT\&I LOx/ethanol RCS thruster

Demonstrations of miniaturized leak-detection sensors supported objectives of significant improvements in safety and operations. The selfcontained sensor system, approximately the size of a postage stamp, allows for easy installation of a device to detect the fuel/oxygen ratio, thereby defining the explosion hazard at a given location.
The PT\&I Project also demonstrated friction-stir welding between two plates of the copperchrome-niobium alloy, GRCop- 84 . The weids proved to have ninety percent of base-metal strength at both room and elevated temperatures. As compared to concepts designed with NARloy$\mathrm{Z}$ (the currently used alloy), the new materials and processes could improve durability and temperature tolerance, especially for reusable engines.

Boeing carried a small-scale cross-feed valve from design to water-flow testing. The crossfeed valve passively allows the transition of propellants from one tank set to another, while the engines are burning, by simply opening the isolation valves on the second set of tanks. Such passive systems required no complicated control circuitry, improving both safety and reliability.

PR\&T also focused on fabricating combustionchamber liners using the Vacuum Plasma Spray (VPS) process - creating liners in a variety of shapes and sizes with GRCop-84. The technique's application also extended to producing a cross-sectional gradient of material, avoiding the need for a separate protective liner for the chamber and nozzle. After more than 100 hotfire tests, the subscale, 5,000-pound-thrust-class, thrust-chamber assembly showed no signs of degradation. The same technology is also being evaluated for coatings on injector faceplates.

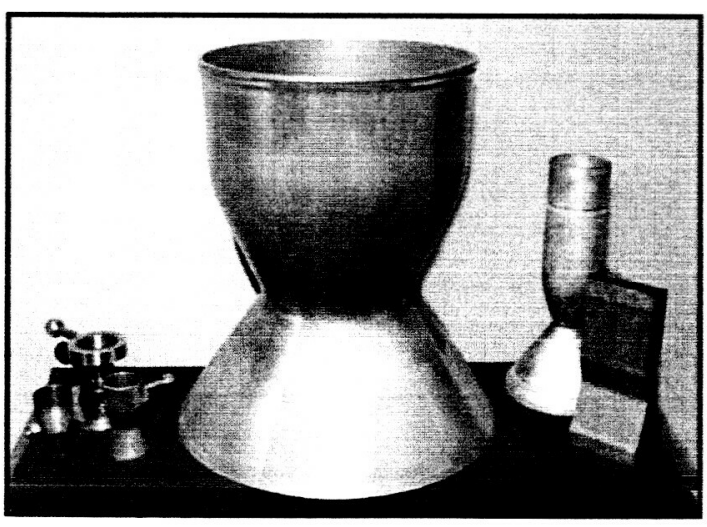

Fig. 10: GRCop-84 rocket-engine components

\section{AIR-BREATHING PROPULSION}

The NGLT projects for air-breathing-propulsion technology originated with ASTP. Two projects 
had plans to culminate in ground-based testing of engine concepts that could have led to the selection of one of propulsion systems for inflight demonstration. The third project provided support for both of these through investments for relevant technology challenges.

\section{$\underline{\text { Rocket Based Combined Cycle }}$}

A Rocket-Based, Combined-Cycle (RBCC) engine has the potential to provide thrust from one integrated, single-duct system for a vehicle that takeoffs like an aircraft and ultimately deliver a payload to orbit. An RBCC engine relies on rocket engines buried within a duct to fire as rockets to produce augmenting, induced-flow thrust at low speeds and then fire fuel-rich through transonic speeds to produce in-duct ramjet combustion. Adjustments to the RBCC duct geometry and fuel-injection system allow it to operate as a scramjet from about Mach 5 to flight in the upper atmosphere, where it reverts to operate purely in rocket mode. The primary advantage of this concept is that "one engine" serves throughout the entire speed range; the challenge is to achieve the requisite levels of performance and operability throughout all modes of operation.

The RBCC Project selected one type of RBCCengine concept to be carried to a high state of technology development - through large-scale, ground-based demonstration - as the "Integrated Systems Test of an Airbreathing Rocket" (ISTAR). The ISTAR concept selected 90-percent hydrogen peroxide and hydrocarbon fuel as propellants for "thrusters" integrated into struts (e.g., strut-rockets) internal to the combustion chamber. (ref. 5). The ISTAR configuration evolved to enable airframe/engine integration for a stub-winged, lifting-body vehicle with external/forebody compression and external/aft expansion.

Risk reduction for the thrusters led to designing and testing a full-scale injector. The last of a series of thruster tests addressed injector-faceheating, performance and combustion-chamber heat flux. The figure shows testing of longduration unit representing one full-scale thruster out of a flight demonstrator scale strut-rocket with a calorimeter installed. Results of the pa- rametric testing proved the viability of the injector/rocket/strut concept.

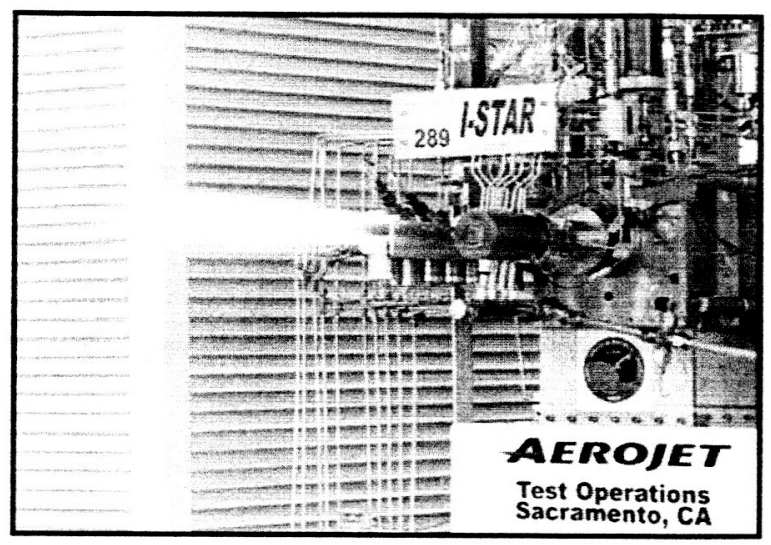

Fig. 11: RBCC strut-injector test

\section{Turbine-Based, Combined Cycle}

The Turbine-Based, Combined-Cycle (TBCC) engine was conceived as an accelerator engine for propulsion from takeoff through Mach 4 (ref. 6). TBCC application is projected for a winged, first-stage vehicle with a scramjet for higherspeed propulsion; that first-stage vehicle would carry a rocket-powered second stage to its highspeed, high-altitude launch point from which to place a payload into orbit.

The project would have culminated in a systemlevel ground test of a TBCC engine at Mach-4 flight conditions. The test results would not only have demonstrated turbine performance and durability for space access but also matured higher-risk, turbine-engine technologies. The ground-test results were expected to validate performance while providing an initial, systemlevel database for dealing with performance, operability, and durability issues.

TBCC Project planning assumed progressing to flight-tests with a flight-qualified version of the $\mathrm{TBCC}$ engine. The resulting X-43-class of flight vehicle could explore critical developmental issues -- especially challenges associated with propulsion/airframe integration and with transition from a "lower-speed" propulsion system (e.g., TBCC) to a scramjet engine. 
The TBCC project passed successfully through a preliminary-design review with General Electric Aerospace Engines (GEAE) as the prime contractor. Computer-based analyses of engine design supported the earlier projects of performance. This engine concept was referred to as the Revolutionary Turbine Engine (RTA).

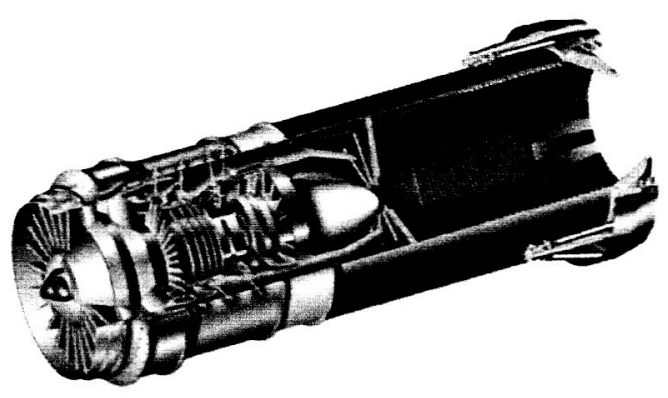

Fig. 12: RTA engine concept

The augmenter increases thrust, in an afterburner-type mode, in addition to thrust provided by the turbine-based flow. RTA tests at GEAE of a trapped-vortex flame holder addressed instability problems associated with traditional augmenter designs. Test results showed stable operation of the proposed flame holder over the range of conditions anticipated for flight. In addition, post-test data analysis has shown good matching to pre-test prediction, thereby validating CFD modeling/design tools for the full augmenter design.

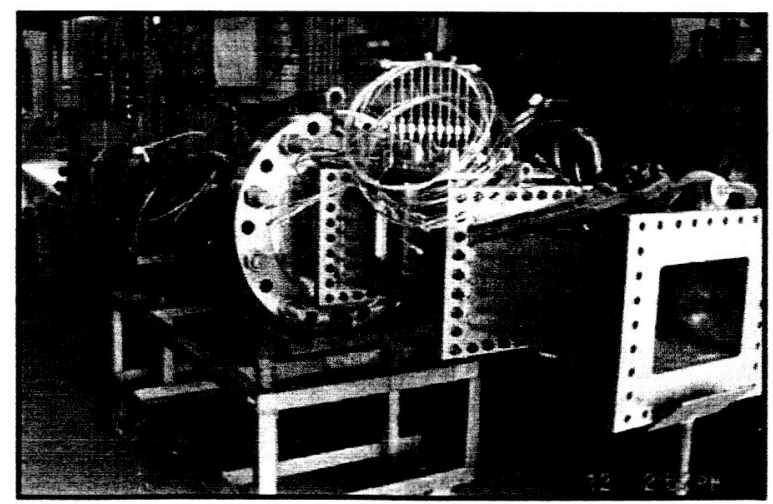

Fig. 13: Flame stability rig installed in test cell

This project also invested in several long-term technologies relevant to the extreme internal temperatures associated space-access missions. Work on high-temperature materials, bearings, and seals focused on meeting mission-based requirements while minimizing thermalmanagement issues (to yieid weight savings at the vehicle level). The successful tests of magnetic bearings at in-flight temperatures and rotating speeds were important since that concept avoids direct-contact transmission of loads except briefly at engine start-up and shut-down.

\section{Propulsion Research and Technology}

The Propulsion Research and Technology (PR\&T) Project has explored new technologies for materials, structures and propulsion-system concepts. PR\&T addressed those technologies to support a full-scale-vehicle demonstration of a hypersonic, air-breathing, propulsion system by year 2015 .

By the end of FY03, the Cooled Panels and Ducts team fabricated five 2.5-by-10-inch, actively cooled, ceramic-matrix-composite (CMC) panels. Such panel concepts could lead to durable, light-weight heat exchangers as walls of a hypersonic, air-breathing engine. The tests of three panels accumulated more than 5-minutes of test time at hypersonic-propulsion-flowpath conditions. The team fabricated, instrumented, and tested one of the concepts as a 6 by 30 -inch, actively cooled, CMC panel. Prior heat exchangers, built from NARloy-Z material, were relatively heavy and demonstrated less than a 50 -mission life -- a factor of ten less than the goal.

PR\&T activity for high-temperature, lightweight structures succeeded in developing a new, hightemperature polyimide (HFPE) that exceeds the prior temperature limit by $200^{\circ} \mathrm{F}$. This material capability can reduce the weight of supporting structures for propulsion systems without sacrificing mechanical properties.

The PR\&T instrumentation team developed thinfilm sensors that yield simultaneous readings of surface temperature, strain, and heat flux on ceramic or metallic components, for use at $590^{\circ} \mathrm{F}$. They achieved a reductions in minimum sensor insulation thickness from 100 to 10 microns plus the capability to simultaneously measure surface 
strain, temperature and heat flux, while doubling life to 200 (temperature-based) cycles.

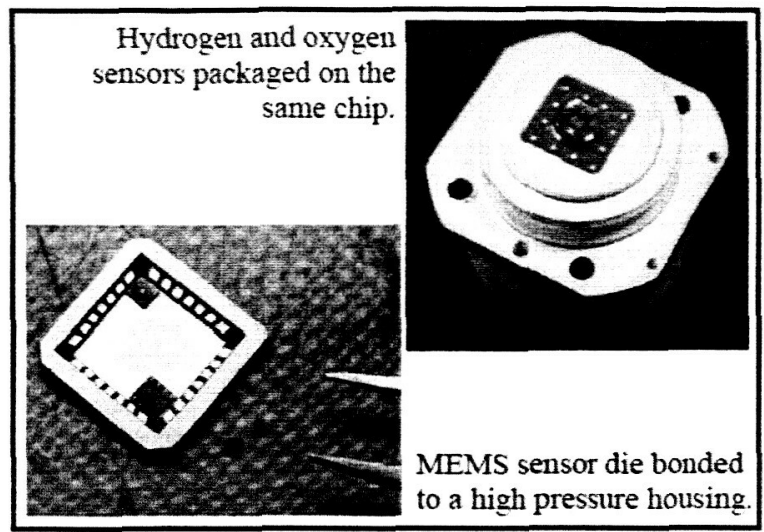

Fig. 14: PR\&T valve leak sensor

The subproject for advanced propellants, in collaboration with the Air Force Research Laboratory, has demonstrated the feasibility of using RP-1 in place of JP-7 in combined-cycle propulsion systems. (JP-7 is no longer in production.) Tests simulating the cooling loads required for a scramjet showed that RP-1 could provide endothermic heat-sink capability equal to that of JP-7.

\section{AIRFRAME SYSTEMS AND VEHICLE OPERATIONS}

This section of the paper covers NGLT hardware-based technological achievements for airframe systems and vehicle operations essentially the entire array of technologies beyond those for engines and closely associated propulsion systems. In a few cases, however, adaptations of the following technologies could find application in "propulsion" projects too.

\section{$\underline{\text { Airframe Structures }}$}

This particular paper does not cover NGLT airframe-structures technologies, which are the subject of a concurrent paper, given by Dr. David Glass (ref. 7). Dr. Glass's paper covers the key NGLT areas of: thermal-protection systems (TPS), propellant tanks, hot/integrated structures and tools for both design and integration of airframe structures. NGLT investments in TPS technology made advances for leading edges, seals and large external surfaces, e.g., "acreage." His paper also provides information on propellant-tank sub-projects - one tank built of metallic material and another of composite material. The list of tasks on hot/integrated structures: includes sensors, active cooling, control surfaces, primary structures and "multifunctional" structures.

\section{Airframe Subsystems}

NGLT investments in vehicle subsystems include developmental work in areas such as power, actuation, avionics and health management. One of the main focuses in this area was to enable an "all-electric" launch vehicle by incorporating electric actuators, thereby eliminating conventional hydraulic systems. Meeting the peak-power demands of the electric actuators required investments in technologies for the associated power system.

One of the power technologies developed under NGLT was for Proton Exchange Membrane (PEM) fuel cells (ref. 8). The PEM fuel-cell technology-development program completed Phase I development of two $2-5 \mathrm{~kW}$ breadboard PEM-fuel-cell power plants; Phase II is progressing through development and environmental test of a $7-10 \mathrm{~kW}$ engineering-model unit.

PEM fuel-cell technology offers many potential advantages over existing alkaline fuel cells: improved performance, lower weight and volume, longer life, reduced hazardous materials, fewer critical failure modes and simpler ground processing. While this work benefits from on-going fuel-cell development for terrestrial use, NASA's focus is on the space-unique aspects of PEM fuel cells and on long-life operation with oxygen instead of air.

NGLT is developing other power technology a "non-toxic" Turbine Power Unit (TPU), in which hydrogen-oxygen gas generator drives a turbo-alternator. Unlike the Shuttle Auxiliary Power Unit (APU), that uses toxic propellants to drive a hydraulic pump, the NGLT-funded TPU drives a generator to produce electrical power. Applications of the TPU technology include power for high-horsepower, all-electric actuation system or electric-pump hydraulic system for 
launch-vehicle flight controls. Potential advantages of the new concept include elimination of toxic fucls, rcduced ground processing, improved reliability and reduced critical failure modes. The schedule of the prototype unit calls for performance tests and completion in September 2004.

In the area of electric actuation, NGLT has supported development of a high-horsepower, failure-tolerant, electro-hydrostatic actuator (EHA). Potential applications for launch vehicle applications range from main-engine, thrust-vector control to movement of flight-control surfaces. When the 50-HP actuator completes testing in September 2004, it will be one of the largest, most powerful electric actuators ever developed for space applications.

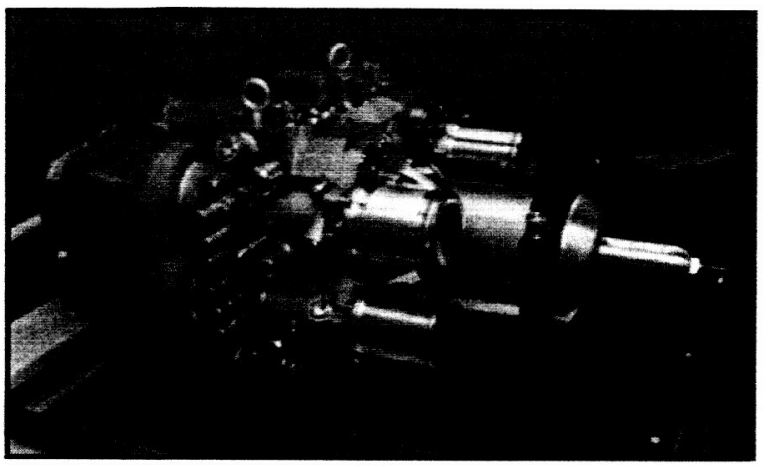

Fig. 15: Prototype, 50hp electro-hydrostatic actuator

\section{$\underline{\text { Launch-Range Operations }}$}

Space-Based Telemetry and Range Safety (STARS) is a space-based communications system to relay telemetry between launch vehicles and the ground. It serves as a proof-of-concept project to determine if operational costs can be reduced and operational flexibility increased. High reliability and extensive coverage are key parameters for judging success.

STARS is composed of two major systems. One, the Range Safety system, includes: (a) a versatile, low-power, multi-channel transceiver, (b) a custom-built flight processor for commandand-data handling, and (c) a commercial Global Positioning System receiver. The transceiver received an up-link (of flight-termination-system commands) and transmitted telemetry data containing tracking data, plus safety-specific health and status indicators. The second major system, a Range User system, provides broadband communications for voice, video, and vehicle/payload data.

In an initial flight demonstration, STARS met all objectives, successfully demonstrating its ability to maintain satellite-communication links between the Tracking and Data Relay Satellite System (TDRSS) and an F-15 aircraft in dynamic flight. The Range Safety telemetry passed its data to four NASA sites (Dryden Flight Research Center, Kennedy Space Center, Goddard Space Flight Center and Wallops Flight Facility) for monitoring. NASA Langley Research Center, NASA Wallops Flight Facility, NASA White Sands Complex, and the Air Force Eastern and Western Ranges also participated in the overall effort.

\section{Aero-thermal Testing}

NGLT investments led to development of improved, optical-based systems for assessing hypersonic, aerodynamic-induced heating. A NASA team completed calibration and acquired prototype data following the development of a faster, high-accuracy, higher-resolution, phosphor-thermography system for use during windtunnel testing. The team also integrated an infrared-image-acquisition system into datareduction software. (The same team provided support with these tools for aero-heating data acquisition during wind-tunnel tests for the Columbia-accident investigation.)

\section{CONCLUDING REMARKS}

NASA's NGLT Program is completing research and development for a wide range of technologies to enable future generations of space-launch transportation systems. Objectives for improving safety, reliability, and affordability extended to providing improvements for application to a vehicle concepts and architectures ranging from those for reusable systems to those for fully expendable launchers. Many projects achieved significant results as evidenced by results, such as those of rocket-system firings, thermo- 
mechanical tests of structures and sensors as well as cryogenic-systems operations.

\section{ACKNOWLEDGEMENTS}

The contributors to this paper included: J. Craig McArthur, Kendall K. Brown, Gary G. Genge, Philip J. Best, Ronald J. Unger, Richard M. Ryan, Dr. Margaret L. Tuma, Dr. Terri L. Tramel, Peter V. Mazurkivich. Jason E. Quinn, Dr. Paul A. Bartolotta, Dr. Mark D. Klem, Scott R. Graham, Sandra K. Elam, Nang T. Pham, Lisa M. Valencia, Charles E. Cockrell, Wanda Simmons and Christi L. Parker.

\section{REFERENCES}

1. Anon.: The Vision for Space Exploration. NASA NP-2004-01-334-HQ, February 2004

2. Vilja, J. and Davis, D.: Next Generation Launch Technology Oxygen-Rich Stage Combustion Prototype Engine -- RS-84. International Astronautics Federation Conference, Bremen, Germany, September 2003.

3. Pearson, N., Pourpoint, T., Anderson, W.E.: Vaporization and Decomposition of Hydrogen Peroxide Drops. AIAA-2003-4642; July 2003
4. Calvignac, J., Dang, L., Tramel, T.L., and Paseur, L.: Design and Testing of Non-Toxic RCS Thrusters For Second Generation Reusable Launch Vehicle. AIAA 203-4922, July 2003

5. Quinn, J.E., ISTAR: Project Status and Ground Test Engine Design. AIAA 2003-5235, July 2003

6. Shafer, D.G. and McNellis, N.B.: Development of a Ground Based Mach 4+ Revolutionary Turbine Accelerator Technology demonstrator (RTATD) for Access to Space. AIAA 20031125, September 2003

7. Glass, D.E.: Airframe Technology Development for Next Generation Launch Vehicles. International Astronautical Congress, Session V.5, October 2004

8. Reaves, W. and Hoberecht, M.: Proton Exchange Membrane (PEM) Fuel Cell Status and Remaining Challenges for Manned Space-Flight Application. 1st International Energy Conversion Engineering Conference. August 2003 